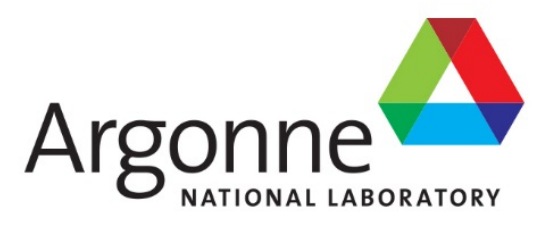

\title{
AMORE Mo-99 Spike Test Results
}

Nuclear Engineering Division 


\begin{abstract}
About Argonne National Laboratory
Argonne is a U.S. Department of Energy laboratory managed by UChicago Argonne, LLC under contract DE-AC02-06CH11357. The Laboratory's main facility is outside Chicago, at 9700 South Cass Avenue, Argonne, Illinois 60439. For information about Argonne and its pioneering science and technology programs, see www.anl.gov.
\end{abstract}

\title{
DOCUMENT AVAILABILITY
}

Online Access: U.S. Department of Energy (DOE) reports produced after 1991 and a growing number of pre-1991 documents are available free via DOE's SciTech Connect (http://www.osti.gov/scitech/).

Reports not in digital format may be purchased by the public from the National Technical Information Service (NTIS):

U.S. Department of Commerce

National Technical Information Service

5301 Shawnee Road

Alexandria, VA 22312

www.ntis.gov

Phone: (800) 553-NTIS (6847) or (703) 605-6000

Fax: (703) 605-6900

Email: orders@ntis.gov

Reports not in digital format are available to DOE and DOE contractors from:

U.S. Department of Energy

Office of Scientific and Technical Information

P.O. Box 62

Oak Ridge, TN 37831-0062

\section{Disclaimer}

This report was prepared as an account of work sponsored by an agency of the United States Government. Neither the United States Government nor any agency thereof, nor UChicago Argonne, LLC, nor any of their employees or officers, makes any warranty, express or implied, or assumes any legal liability or responsibility for the accuracy, completeness, or usefulness of any information, apparatus, product, or process disclosed, or represents that its use would not infringe privately owned rights. Reference herein to any specific commercial product, process, or service by trade name, trademark, manufacturer, or otherwise, does not necessarily constitute or imply its endorsement, recommendation, or favoring by the United States Government or any agency thereof. The views and opinions of document authors expressed herein do not necessarily state or reflect those of the United States Government or any agency thereof, Argonne National Laboratory, or UChicago Argonne, LLC. 


\section{AMORE Mo-99 Spike Test Results}

by

Amanda J. Youker, John F. Krebs, Kevin J. Quigley, James P. Byrnes, David A. Rotsch, Thomas Brossard, Ken Wesolowski, Kurt Alford, Sergey Chemerisov, and George F. Vandegrift Nuclear Engineering Division, Argonne National Laboratory

September 27, 2017 



\section{CONTENTS}

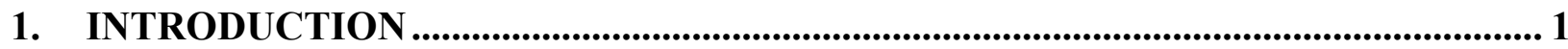

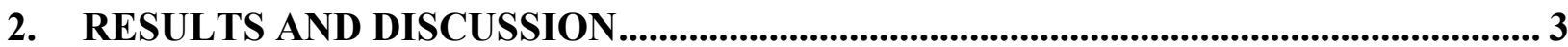

2.1 Sample Retrieval Problems and Solution................................................................ 3

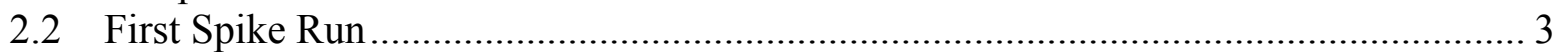

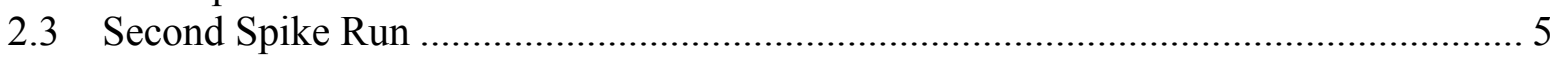

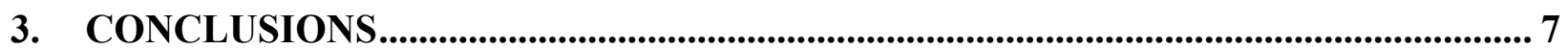

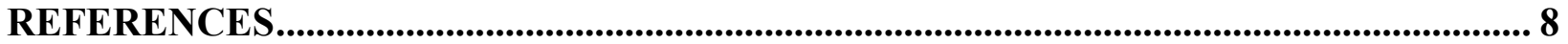

\section{FIGURES}

1 Flow diagram for the AMORE separation system housed in a shielded glovebox.

2 A plot of $\mathrm{NaOH}$ volume versus Mo-99 activity based on the column stripping samples collected via the column stripping ladder in the AMORE glovebox.

3 A plot of $\mathrm{NaOH}$ volume versus Mo-99 activity based on the column stripping samples collected via the column stripping ladder in the AMORE glovebox.

\section{TABLES}

1 Gamma counting results for samples retrieved from the first Mo-99 spike test....................4

2 Gamma counting results for samples retrieved from the second Mo-99 spike test................6 
This page intentionally left blank. 


\section{INTRODUCTION}

With funding from the National Nuclear Security Administrations Material Management and Minimization Office, Argonne National Laboratory (Argonne) is providing technical assistance to help accelerate the U.S. production of Mo-99 using a non-highly enriched uranium (non-HEU) source. A potential Mo-99 production pathway is by accelerator-initiated fissioning in a subcritical uranyl sulfate solution containing low enriched uranium (LEU). As part of the Argonne development effort, we are undertaking the AMORE (Argonne Molybdenum Research Experiment) project, which is essentially a pilot facility for all phases of Mo-99 production, recovery, and purification. Production of Mo-99 and other fission products in the subcritical target solution is initiated by putting an electron beam on a depleted uranium (DU) target; the fast neutrons produced in the DU target are thermalized and lead to fissioning of U-235. At the end of irradiation, Mo is recovered from the target solution and separated from uranium and most of the fission products by using a titania column. The Mo is stripped from the column with an alkaline solution. After acidification of the Mo product solution from the recovery column, the Mo is concentrated (and further purified) in a second titania column. The strip solution from the concentration column is then purified with the LEU Modified Cintichem process. A full description of the process can be found elsewhere [1-3].

The initial commissioning steps for the AMORE project include performing a Mo-99 spike test with $\mathrm{pH} 1$ sulfuric acid in the target vessel without a beam on the target to demonstrate the initial Mo separation-and-recovery process, followed by the concentration column process. All glovebox operations were tested with cold solutions prior to performing the Mo-99 spike tests. Two Mo-99 spike tests with $\mathrm{pH} 1$ sulfuric acid have been performed to date.

Figure 1 shows the flow diagram for the remotely operated Mo-recovery system for the AMORE project. There are two separate pumps and flow paths for the acid and base operations. The system contains three sample ladders with eight sample loops per ladder for target mixing; column loading, including acid and water washes; and column stripping, including the final water wash. 


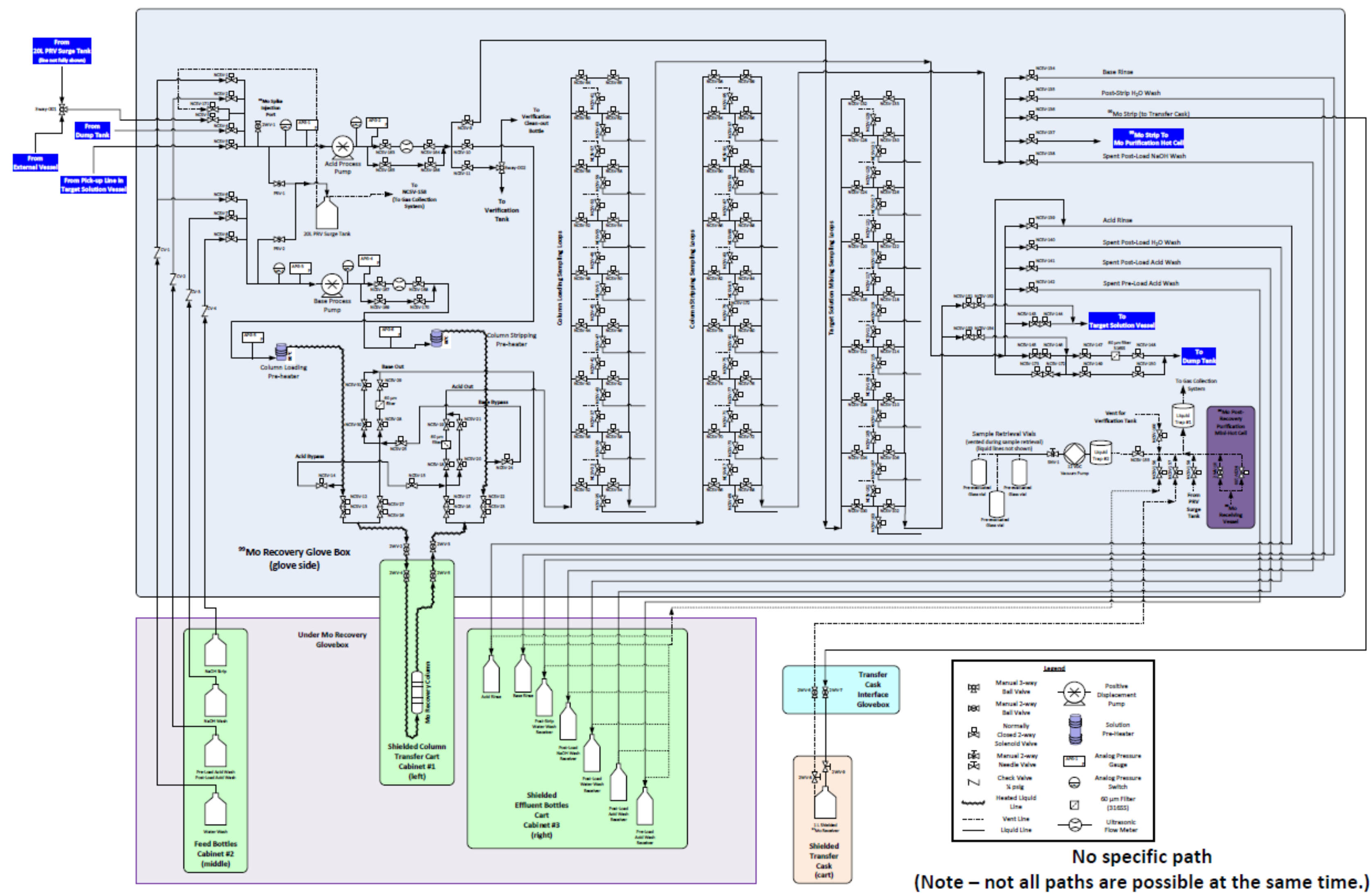

FIGURE 1. Flow diagram for the AMORE separation system housed in a shielded glovebox. 


\section{RESULTS AND DISCUSSION}

\subsection{Sample Retrieval Problems and Solution}

Results have shown a $10-20 \%$ dilution effect for samples retrieved by means of the sample loops; in other words, $10-20 \%$ of residual solution is left in the loops after they have been "emptied." Additionally, after the loops were washed three times and samples were retrieved after each wash, the loops still contained residual solution. With this in mind, a nitrogen purge of all loops prior to washing was added for the second Mo-99 spike test and helped to remove more residual Mo-99 activity compared to the amount of residual activity found in the first Mo-99 spike test, when samples were not purged with nitrogen.

In the first Mo-99 spike test, the target mixing samples showed that $13 \%$ of the original Mo-99 activity remained in the loops after they were flushed with acid for 1 minute. After a second wash of the loops with acid for 1 minute, a third set of samples showed that $0.08 \%$ of the original activity remained.

For the column loading loops, the Mo-99 activities found in the samples after the first and second washes were below minimum detecactivities $\left(<9 \times 10^{-4} \mu \mathrm{Ci}\right)$. For the column stripping samples, washing the loops twice with water for 1 minute and retrieving samples after each wash showed that $7 \%$ and $4 \%$ of the Mo-99 found in the original sample remained.

In an effort to remove more residual Mo-99 during the washing steps, after each set of samples was retrieved, all of the loops were purged with $\mathrm{N}_{2}$ prior to being washed with liquid for the second Mo-99 spike test. For the target mixing samples, $2 \%$ of the original Mo-99 activity remained after the loops were purged with $\mathrm{N}_{2}$ and washed with acid for 1 minute. The target mixing loops were purged with $\mathrm{N}_{2}$ and washed with acid for 1 minute a second time, and $0.8 \%$ of the original activity remained. The column loading samples that were retrieved after purging with $\mathrm{N}_{2}$ and washing with acid for 1 minute were reported as minimum detecactivities $\left(<4 \times 10^{-4} \mu \mathrm{Ci}\right)$. After a single purge with $\mathrm{N}_{2}$ and a water wash for 1 minute, $0.9 \%$ of the original Mo-99 activity remained in the column stripping loops. After a second purge with $\mathrm{N}_{2}$ and a water wash for 1 minute, $0.03 \%$ of the original Mo-99 activity remained in the loops.

Results from the two spike tests are discussed below.

\subsection{First Spike Run}

Table 1 shows the results for the first Mo-99 spike test. The Mo-99 activity in the target mixing samples retrieved via the target mixing ladder was at least $15 \%$ low based on the amount of activity found in the recovery column (RC) product or feed for the concentration column (CC). The RC feed sample taken from the verification tank gave an artificially high Mo-99 activity because the same $1 / 16^{\text {th }}$-in. tubing that was used to introduce the Mo-99 spike into the verification tank was used to retrieve the feed sample. Little to no activity was found in the column effluent, acid wash, or water wash samples for the RC and CC operations. 
Due to an issue with LabView shutting down, a final water wash of the column was not done for the first Mo-99 spike test. The percent Mo-99 recovered values are based on the single collected feed sample of $47 \mathrm{mCi}$, which explains why the Mo-99 recoveries for the CC feed and $\mathrm{CC}$ product are $>100 \%$. Some of the individual samples were not retrieved because the vacuum pump trap was holding too much vacuum, which prevented some of the solenoid valves from opening. A smaller trap was installed for the second Mo-99 spike test.

TABLE 1. Gamma counting results for samples retrieved from the first Mo-99 spike test.

\begin{tabular}{lcc}
\hline \multicolumn{1}{c}{ Sample } & $\begin{array}{c}\text { Mo-99 } \\
\text { Activity } \\
\text { (mCi) }\end{array}$ & \% Mo-99* \\
\hline & & \\
Target Mixing Feed - RC & 47 & 100 \\
Column Effluent - RC & 0.03 & 0.06 \\
Acid Wash - RC & 0.004 & 0.01 \\
Water Wash - RC & 0.02 & 0.05 \\
Mo-99 Product - RC/ Feed - CC & 55 & 117 \\
Column Effluent - CC & 0.01 & 0.02 \\
Acid Wash - CC & 0.0004 & 0.001 \\
Water Wash - CC & 0.0005 & 0.001 \\
Mo-99 Product - CC & 55 & 118 \\
Waste - CC & 0.04 & 0.07 \\
\hline \%Mo-99 is based on the target mixing feed sample, which \\
does not accurately represent the Mo-99 activity loaded onto \\
the RC.
\end{tabular}

Figure 2 shows stripping data for the Mo-99 product eluted from the titania RC for the first Mo-99 spike test based on stripping samples that were retrieved via the column stripping ladder in the AMORE glovebox. Results indicate that the majority of the Mo-99 is recovered in the first $\sim 700 \mathrm{~mL}$ of $1 \mathrm{M} \mathrm{NaOH}$, which is surprising because the base heater was not working for this experiment. The column was heated to $80^{\circ} \mathrm{C}$, but the strip solution was not heated. The amount of strip solution represents 5.6 column volumes (CVs) and suggests that significantly less strip solution (when $1 \mathrm{M} \mathrm{NaOH}$ is used) is required to strip the Mo-99 product from the RC. If the final Mo-99 spike test shows the same type of behavior, the amount of strip solution may be decreased to $10 \mathrm{CVs}$ from $20 \mathrm{CVs}$ for the AMORE experiments with uranyl sulfate. 


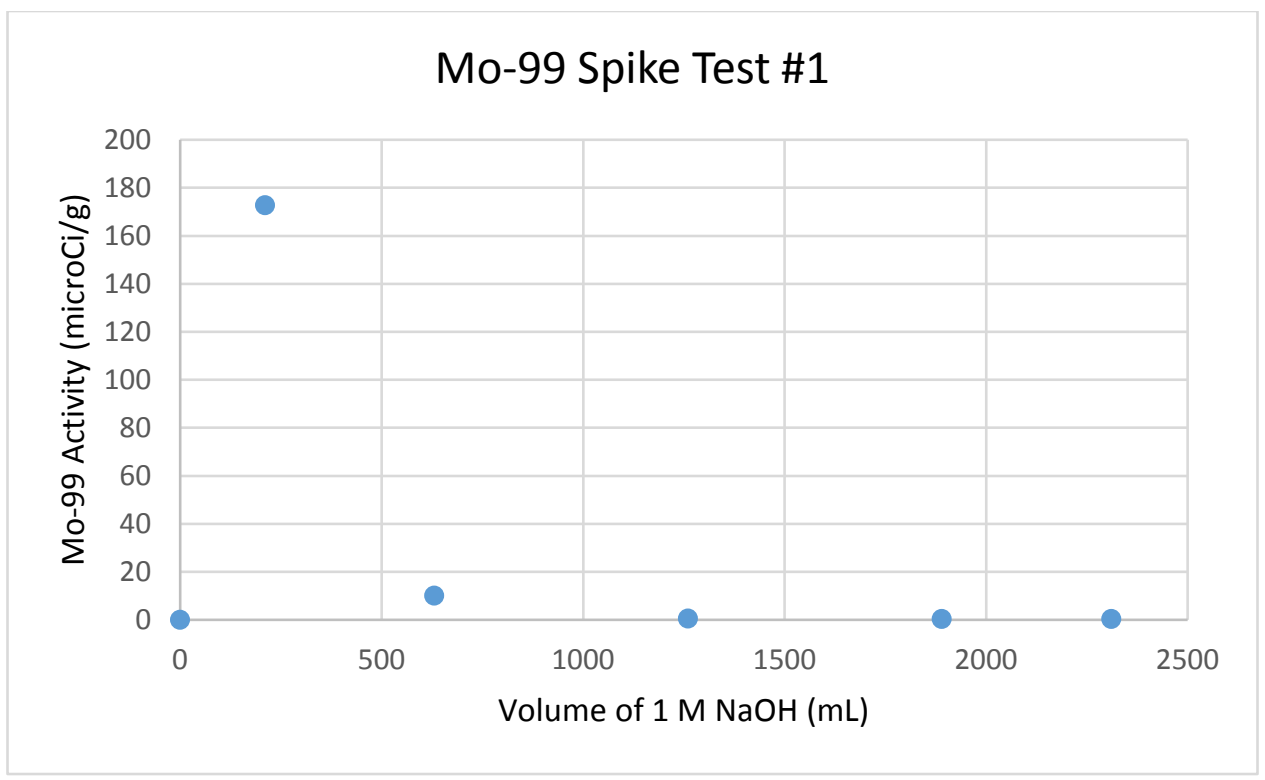

\section{FIGURE 2. A plot of NaOH volume versus Mo-99 activity based on the column stripping samples collected via the column stripping ladder in the AMORE glovebox.}

\subsection{Second Spike Run}

Table 2 shows the results for the second Mo-99 spike test. A sample was taken from the verification tank after the Mo-99 spike was added, and the solution was thoroughly mixed for 2 hours. The verification tank sample collected for the second Mo-99 spike test was taken via an external vessel and did not employ the same tubing that was used to introduce the Mo-99 spike into the verification tank. Once the uranium irradiations began, a feed sample could not be taken until after irradiation when entry into hot cell one is allowed. For this Mo-99 spike test, a few hundred milliliters of feed solution was purposely not loaded on the column to test a different way of retrieving a feed sample for future irradiations with uranium. The solution remaining in the target vessel was pumped into the verification tank, and the solution was circulated in a loop that goes in and out of the verification tank. A sample was taken via the syringe port manually; however, the Mo-99 activity in this sample was 50\% low. Based on these results, it appears that either the loop was filled with acid solution, or the path from the target vessel to the verification tank was filled with acid prior to the solution being pumped from the target vessel, causing the activity to be $\sim 50 \%$ low. For the next Mo-99 spike test with beam on target, all paths will be purged with $\mathrm{N}_{2}$ prior to pulling the unloaded solution from the target vessel to the verification tank.

The Mo-99 product from the RC or the feed for the $\mathrm{CC}$ showed low activity because the air purge line to mix the solution in the BigFoot hot cell had cracked, and the solution was not mixed prior to collecting a sample. Little to no activity was found in the column effluent, acid wash, or water wash samples for the RC and CC operations. Results from the overall process show that $92 \%$ Mo-99 was recovered. During this test, there were still issues with the sample retrieval process related to the column stripping ladder. Only four of the eight samples were 
retrieved each time during actual sample retrieval and sample retrieval during the washout steps. Part of the $1 / 16^{\text {th }}$-in. tubing appeared to be kinked, and the sampling manifolds needed to be redone for several of the loops on the column stripping ladder. These issues will be remedied before the next Mo-99 spike test with beam on target.

TABLE 2. Gamma counting results for samples retrieved from the second Mo-99 spike test.

\begin{tabular}{|c|c|c|}
\hline Sample & $\begin{array}{c}\text { Mo-99 } \\
\text { Activity } \\
\text { (mCi) }\end{array}$ & $\%$ Mo-99* \\
\hline Verification Tank Feed - RC & 37 & 100 \\
\hline Target Mixing Feed - RC & 30 & 81 \\
\hline Unloaded Feed in Target Vessel via Syringe Port - RC & 19 & 51 \\
\hline Column Effluent - RC & 0.06 & 0.2 \\
\hline Acid Wash - RC & 0.003 & 0.01 \\
\hline Water Wash - RC & 0.03 & 0.08 \\
\hline Mo-99 Product $-\mathrm{RC} /$ Feed $-\mathrm{CC}$ & 26 & 70 \\
\hline Acid Wash - CC & 0.0005 & 0.001 \\
\hline Water Wash - CC & 0.0300 & 0.08 \\
\hline Mo-99 Product - CC & 34 & 92 \\
\hline Waste $-\mathrm{CC}$ & 0.03 & 0.08 \\
\hline
\end{tabular}

Figure 3 shows the stripping data for the Mo-99 product eluted from the titania RC for the second Mo-99 spike test based on stripping samples that were retrieved via the column stripping ladder in the AMORE glovebox. The strip solution prior to entry on the column and the column itself were both heated to $80^{\circ} \mathrm{C}$. Results indicate that the majority of the Mo- 99 was recovered in the first $\sim 1100 \mathrm{~mL}$ of $1 \mathrm{M} \mathrm{NaOH}$. This represents $8.8 \mathrm{CVs}$ and suggests that less strip solution (when $1 \mathrm{M} \mathrm{NaOH}$ is used) is required to strip the Mo-99 product from the RC. For the final Mo-99 spike test with beam on target, the amount of strip solution will be decreased to $10 \mathrm{CVs}$ from $20 \mathrm{CVs}$. 


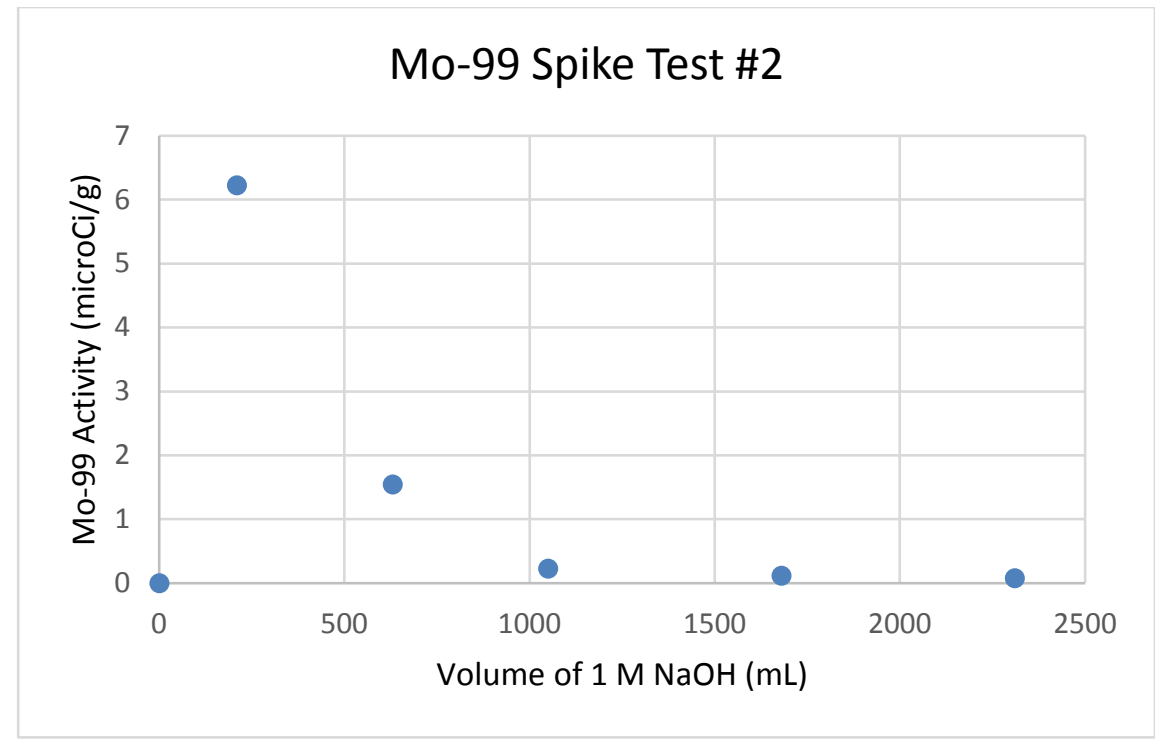

FIGURE 3. A plot of $\mathrm{NaOH}$ volume versus Mo-99 activity based on the column stripping samples collected via the column stripping ladder in the AMORE glovebox.

\section{CONCLUSIONS}

Overall, the amount of Mo-99 recovered from the RC and CC operations for the first two spike tests was good. In the first Mo-99 spike test, it is difficult to determine the overall \%Mo-99 recovery because we do not have a good value for the feed solution; however, if we assume the target mixing sample is $20 \%$ low, the amount of Mo-99 loaded onto the RC would be $56.4 \mathrm{mCi}$. With $55 \mathrm{mCi}$ Mo-99 recovered in the CC product, the overall recovery would be $98 \%$. The amount of Mo-99 recovered in the second Mo-99 spike test was 92\%. Comparing Figures 2 and 3 , the $\mu \mathrm{Ci} / \mathrm{g}$ Mo-99 in the first strip sample for spike test $\# 1$ and spike test $\# 2$ are significantly different. In the first spike test, the activity was $178 \mu \mathrm{Ci} / \mathrm{g}$ in the first strip sample, and in the second spike test, the activity was $6 \mu \mathrm{Ci} / \mathrm{g}$. Also, in the first spike test, less strip solution was required to fully strip Mo-99 from the RC compared to the second spike test. The fact that the strip solution was not heated in the first spike test makes these results even more surprising. With the strip solution being heated to $80^{\circ} \mathrm{C}$ in the second spike test, the first strip sample may not have been taken early enough in the strip process to see the higher activity. In the next Mo-99 spike test, samples will be taken earlier than 5 minutes after stripping at $84 \mathrm{~mL} / \mathrm{min}$. Nonetheless, strip results from both spike tests suggest less than $20 \mathrm{CVs}$ of $1 \mathrm{M} \mathrm{NaOH}$ can be used to fully remove Mo-99 from the RC.

Lessons were learned during the first two spike tests related to removal and installation of the verification tank, column, and effluent cart. Additionally, the sample retrieval process is still being improved, and new needle assemblies will be built for the column stripping ladder for the next Mo-99 spike test with beam on target. A third spike test will be performed to test these improvements before uranium irradiation experiments begin. 


\section{REFERENCES}

[1] Krebs, J.F., Byrnes, J.P., Hebden, A.S., Quigley, K.J., Youker, A.J., Chemerisov, S.D., and Vandegrift, G.F. "Remotely Operated Systems for Primary Recovery of ${ }^{99}$ Mo from Accelerator-Driven Sub-Critical Fission of LEU," presented at the 2016 Mo-99 Topical Meeting, St. Louis, Mo, September 11-14, 2016.

[2] Youker, A.J., Chemerisov, S.D., Tkac, P., Kalensky, M., Heltemes, T.A., Rotsch, D.A., Vandegrift, G.F., Krebs, J.F., Makarashvili, V. Stepinski, D.C. "Fission Produced ${ }^{99} \mathrm{Mo}$ without a Nuclear Reactor." J. Nucl. Med. 2016, 116, 181040.

[3] Youker, A.J., Chemerisov, S.D., Tkac, P., Kalensky, M., Heltemes, T.A., Rotsch, D.A., Krebs, J.F., Makarashvili, V., Stepinski, D.C., Alford, K., Bailey, J., Byrnes, J., Gromov, R., Hafenrichter, L., Hebden, A., Jerden, J., Jonah, C., Micklich, B., Quigley, K., Schneider, J., Sun, Z., Wesolowski, K., and Vandegrift, G.F. "Compendium of Phase-I Mini-SHINE Experiments.” ANL/NE-16/39, October 2016 (http://www.ipd.anl.gov/anlpubs/2017/01/ 131828.pdf). 



\section{Argonne}

Nuclear Engineering Division

Argonne National Laboratory

9700 South Cass Avenue, Bldg. 208

Argonne, IL 60439-4854

www.anl.gov 